lines which happens in medicine, the prevalence and incidence of the differential diagnoses having an important bearing on the reasoning process. ${ }^{5}$ The convention of substantiating the "knowledge" used by pointing to actual observations is linked closely to this type of reasoning. ${ }^{45}$ Perhaps "witchdoctors" (31 October, p 1108) are those who persistently scuttle away from such illuminating observations and open logical thought processes.

When we are actually talking to patients or examining them, we tend to interpret information quickly using subconscious thought processes. If we wish to explain our reasoning to patients or other doctors, however, we must use explicit, logical reasoning which often begins with "leads", and be prepared to substantiate the knowledge used. Perhaps this dual nature of the logic of medicine should have been emphasised.

D E H LLEWELYN

Department of Medicine,

King's College School of Medicine and Dentistry,

London SE5 8RX

1 Llewelyn DEH. Mathematical analysis of the diagnostic relevance of clinical findings. Clin Sci 1979;57:477-9.

2 Llewelyn DEH. Accuracy and value of the haemoccult test. BrMed f 1983;285:1144-5.

3 Eddy DM, Clanton CH. The art of diagnosis. $N$ Engl 7 Med 1981;36:1263-8.

4 Llewelyn DEH. Applying the principle of logical elimination to probabilistic diagnosis. Med Inf (Lond) 1981;6:25-32.

5 Llewelyn DEH. The mathematics of clinical diagnosis. In: Rodbard D, Forti G, eds. Computers in endocrinology. New York: Raven Press, 1984:299-331.

\section{Recent theories on the cause of cot death}

SIR,-In his review (28 November, p 1366) Professor A D Milner divides all the hypotheses on the cause of cot deaths introduced in the past 10 years into four categories but fails to mention one which clearly belongs to the group which he has labelled "maturation failure."

This theory-which assumes that a high proportion of childhood cancers are initiated during embryogenesis ${ }^{2}$-ascribes maturation failure to a latent period effect of one of these embryomas (juvenile myeloid leukaemia). It was originally introduced 12 years ago to explain $(a)$ why there was overrepresentation of summer and autumn births among cot deaths and underrepresentation of these births among equally young patients with leukaemia, and $(b)$ why there are so few myeloid cases among childhood leukaemias. ${ }^{3}$ But it was reintroduced a few months ago to explain why cot deaths as well as juvenile myeloid leukaemia have associations with exceptionally high levels of fetal haemoglobin. ${ }^{45}$

A high proportion of embryomas among juvenile leukaemias would allow these cases to have associations with faulty maturation of blood corpuscles and consequent difficulty in replacing either passive with active immunity (faulty leucopoiesis) or fetal with adult haemoglobin (faulty erythropoiesis). The first difficulty would affect lymphatic as well as myeloid embryomas, but the second would affect only the myeloid subgroup. Furthermore, infants who had survived the neonatal period in spite of one or both difficulties would be at high risk of dying either from a minor infection (myeloid and lymphatic embryomas) or from tissue anoxia (myeloid embryomas). Finally, this difference between otherwise similar neoplasms would be more noticeable today than it was before antibiotics had reduced the risk of death from infection without affecting sudden deaths of apparently healthy infants.

In short, besides providing a reason why cot deaths are concentrated between 1 and 6 months of age, this "maturation failure" hypothesis would account for the high incidence of lymphatic leukaemia among 2 to 4 year olds and for the emergence of relatively high mortality from leukaemia after the discovery of drugs which compensate for defective immune responses. It is also a hypothesis which invites further testing of $\mathrm{HbF}$ and $\mathrm{HbA}$ concentrations in cases of unexplained stillbirths, cot deaths, and deaths from respiratory infection in young infants.

Cancer Epidemiology Research Unit,

\section{A M STEWART}

Queen Elizabeth Hospital

Birmingham B15 2TH

1 Stewart AM. Competing causes of death in young cases of myeloid leukaemia. Paediatr Perinat Epidemiol 1987;1:197-8.

Knox EG, Marshall T, Barling RT. Leukaemia and childhood cancer in twins. F Epidemiol Community Health 1984:38:12-6. cot deaths. $\mathrm{Br} \mathrm{Med} \mathcal{f}$ 1975;ii:605-7.

4 Giulian GG, Gilbert EF, Moss RL. Elevated fetal haemoglobin levels in sudden infant death syndrome. $N$ Engl $7 \mathrm{Med}$ 1987;316:1122-6.

5 Weatherall DJ, Edwards JA, Donahue WTA. Haemoglobin and red cell enzyme changes in juvenile myeloid leukaemia. BrMed f 1968;i:679-81.

\section{Computerised advice on malaria prevention} and immunisation

SIR,-Drs Angela J Williams and David J M Lewis (5 December, $p$ 1449) highlight the problem of disseminating accurate antimalarial and pretravel health advice. We share their concern, ${ }^{1-3}$ especially as surveys undertaken in Glasgow between 1977 and 1985 indicated that $36 \%$ of the 13816 overseas travellers who were interviewed on their return reported illness-much of which might have been prevented. Moreover, in the past 10 years 703 patients with malaria have been recorded in Scotland.

These findings all emphasise the need for a source of continually updated information on suitable antimalarial drugs for travellers and appropriate immunisations. Since January 1987 this has been available on a database compiled by the Communicable Diseases (Scotland) Unit $(\mathrm{CD}(\mathrm{S}) \mathrm{U})$ and installed by the Scottish Poisons Bureau Information Service on its mainframe computer. General practitioners who have access to a terminal or computer with a modem (such as that which links with Prestel) can register to use the service by contacting the $\mathrm{CD}(\mathrm{S}) \mathrm{U}$ (telephone 0419467120 ext 247)

This service covers recommended immunisations and malaria prophylaxis and is updated directly from the unit on the basis of advice from various sources, including the World Health Organisation, the Department of Health and Social Security, the Malaria Reference Laboratory, embassies, and drug companies. Information about the administration and availability of both common and more unusual vaccines is also provided. Direct feedback is encouraged so that the information can be improved. A modified version of the database will be made available soon to other interested parties such as airlines, travel agencies, and businesses.

It is hoped that this use of modern technology will help the medical profession to minimise preventable illness in travellers and reduce the costs associated with travel related illnesses.

JONATHAN H COSSAR ERIC WALKER DANIEL REID ROBERT D DEWAR

Ruchill Hospital,

Glasgow G20 9NB

1 Cossar JH, Reid D, Grist NR, et al. Illness associated with international travel: a ten year review. Travel Medicine International 1985;3:13-8.
2 Reid D, Cossar JH, Ako TI, Dewar RD. Do travel brochures give adequate advice on avoiding illness? $\mathrm{Br}$ Med $\mathcal{F}$ 1986;293:1472. Walker E, Quayyum A. Malaria in Scotland and its presentatio in a Glasgow hospital. Health Bull (Edinb) 1981;39:281-6.

\section{Rare tumour system}

SIR,-We are indebted to you for bringing to our attention the Leeds Oncology Information Centre (28 November, $p$ 1421). This organisation receives and collates information on the management of rare cancers and facilitates exchange of information between oncologists. For some time in this oncology unit we have considered floating the idea of a national rare tumour register to gather as much data as possible about the diagnosis, management, and treatment of such uncommon neoplasms.

The situation that obtains at the moment is unsatisfactory. A clinician encountering a rare tumour must review the published reports, which is time consuming, and the desired information is often incomplete. Many of these reports are case reports, often published as curiosities to expand a curriculum vitae for professional advancement. Because of the nature of case reports details tend to be scanty and their value may be lost in the mountain of papers produced each year.

We would propose the establishment of a central rare tumour register which would receive fully detailed accounts of any rare tumour covering all aspects of the disease. These accounts would amount to a detailed discharge summary. On receipt and acceptance the doctor submitting the report would be credited with a rare tumour register citation number. This number would be acceptable for inclusion on a curriculum vitae as a publication. This system would encourage those in training to submit such reports and would avoid the tedium of revising and redrafting less complete case reports for publication in journals. Such a system would require the active support of bodies such as the BMA, the royal colleges, and the Department of Health and Social Security so that the rare tumour register citation attained some status. Once the central registry had accumulated sufficient cases we would expect that authoritative monographs could be produced and would furnish a very useful source of information for the clinician confronted with the management of unusual tumours.

J J BOLGER D A Williams J GOEPEL

Weston Park Hospital,

Sheffield S10 2SJ

\section{Intervention by general practitioners to} reduce smoking

SIR,-Dr M A H Russell and colleagues (14 November, p 1240) addressed an important issue in their study of the effects of interventions by general practitioners to help people stop smoking. In summarising their findings they state that "brief intervention given without the support and back up of the local smokers' clinic had no detectable advantage over general practitioners' usual care." They also conclude that the supported brief intervention procedure "significantly increased the success rate." We believe, however, that methodological flaws in the study design cast doubt on these conclusions.

Though the authors report that there was no significant difference in either self reported or "adjusted" abstinence rates between the unsupported brief intervention and usual care groups, several design issues render this finding difficult to interpret. Firstly, the usual care that was provided was neither described nor monitored. It is quite 